\title{
Alcohol consumption, cigarette smoking, and endometrial cancer risk: results from the Netherlands Cohort Study
}

\author{
Adrian Loerbroks • Leo J. Schouten • \\ R. Alexandra Goldbohm • Piet A. van den Brandt
}

Received: 20 November 2006/ Accepted: 12 February 2007/Published online: 16 April 2007

(C) Springer Science+Business Media B.V. 2007

\begin{abstract}
Objective To examine the association between alcohol consumption, cigarette smoking, and endometrial cancer.

Methods In 1986, the Netherlands Cohort Study was initiated. A self-administered questionnaire on dietary habits and other cancer risk factors was completed by 62,573 women. Follow-up for cancer was established by record linkage to the Netherlands Cancer Registry.

Results After 11.3-years of follow-up, 280 incident endometrial cancer cases were available for analyses. In multivariate analysis, the rate ratio (RR) for alcohol users versus non-users was 1.06 (95\% Confidence Interval (95\% $\mathrm{CI})=0.78-1.43)$. There were neither dose-dependent trends nor associations with different types of beverages. The RR for former and current smokers versus neversmokers was $0.83(95 \% \mathrm{CI}=0.58-1.20)$ and $0.59(95 \%$ $\mathrm{CI}=0.40-0.88)$, respectively. These estimates did not change significantly when body mass index (BMI) and age at menopause were added to the models.

Conclusions There is no association between alcohol consumption and endometrial cancer. Current smoking is associated with a reduced risk of endometrial cancer. This association is neither mediated by BMI nor by age at menopause.
\end{abstract}

\footnotetext{
A. Loerbroks · L. J. Schouten $(\bowtie) \cdot$ P. A. van den Brandt Department of Epidemiology, Nutrition and Toxicology Research Institute Maastricht (NUTRIM), Maastricht University, PO Box 616, 6200 MD Maastricht, The Netherlands e-mail: 1j.schouten@epid.unimaas.nl

R. A. Goldbohm

Business Unit Food \& Chemical Risk Analysis, TNO Quality of Life, Utrechtseweg 48, PO Box 360, 3704 HE Zeist, The Netherlands
}

Keywords Alcohol drinking - Smoking · Endometrial neoplasms $\cdot$ Cohort studies $\cdot$ Netherlands

\section{Introduction}

Endometrial cancer is the most frequently diagnosed gynecologic cancer in Europe [1]. The development of endometrial cancer has been related to exposure to estrogens unopposed by progestagens [2]. Many studies have shown a positive association between alcohol ingestion and estrogen levels in postmenopausal women. For instance, cross-sectional data from the European Prospective Investigation into Cancer and Nutrition (EPIC) suggested that elevated blood levels of estrone are observed with increasing alcohol consumption in postmenopausal women [3]. Thus, alcohol could be expected to increase endometrial cancer risk by elevating estrogen levels. An important determinant of estrogen levels in women is use of unopposed hormone replacement therapy (HRT). Accordingly, use of unopposed HRT is consistently associated with an increased risk of endometrial cancer [4-6]. Furthermore, it has been suggested that alcohol consumption increases estradiol levels in particular in postmenopausal women who are on HRT [7, 8]. However, previous studies have indicated that alcohol consumption is either weakly or not associated with a reduced risk of endometrial cancer and no significant interaction with use of HRT has been found [9]. Although several studies have analyzed the association between alcohol consumption and endometrial cancer risk [10-22], only few studies have examined the risk associated with various measures of alcohol consumption (e.g., amount and type of alcohol) including only one comprehensive prospective cohort study [18]. 
In contrast to alcohol, smoking has been hypothesized to exert anti-estrogenic effects [23] and to lower the risk of endometrial cancer in this way. Also, an effect modification by use of HRT seems reasonable [24]. Furthermore, it has been suggested that body mass index (BMI) and age at menopause might mediate part of the inverse association between smoking and endometrial cancer [24]. Earlier prospective studies [22, 25-29] have generally suggested that smoking is associated with a slight to moderate protection against endometrial cancer. However, to date, only the largest and most recent prospective cohort study has reported a significantly reduced risk in both current and past smokers [29]. Moreover, this large study explored the relationship between HRT and smoking and found no effect-modification, and also found that the association between smoking and endometrial cancer was not confounded by alcohol use [29]. The evidence from other epidemiological studies with regard to an effectmodification by use of HRT is ambiguous [24].

As many case-control [24], but only a few cohort studies have reported on the association between smoking and endometrial cancer [22, 25-29], the International Agency for Research on Cancer concludes that prospective cohort studies, in which selection and recall bias are minimized, are scarce [30]. Only two cohort studies have explored the association between smoking and endometrial cancer comprehensively by examining the risk associated with all common quantitative smoking measures (e.g., smoking duration, time since cessation) [28, 29].

Since only few prospective cohort studies have investigated the association between alcohol consumption, cigarette smoking, and endometrial cancer comprehensively, important features of this relationship are under-explored. Hence, we aim to provide additional evidence based on prospective data. Moreover, we intend to elucidate the hormonal mechanisms underlying endometrial carcinogenesis by investigating, first, whether BMI and age at menopause might act as intermediary variables in the association between smoking and endometrial cancer and by examining, second, whether there is evidence regarding a potential effect modification by HRT use.

\section{Materials and methods}

The Netherlands Cohort Study (NLCS) started in September 1986 when 62,573 women aged 55-69 years were enrolled in the cohort. Ethical approval was obtained from the ethics committee of the University Hospital Maastricht. All women were presumed to be postmenopausal. At baseline, data on dietary habits and other risk factors (such as alcohol consumption, smoking history, reproductive history, and anthropometry) were collected by means of a self-administered questionnaire. Data analysis was conducted according to the case-cohort approach. In this approach, cases are derived from the cohort (providing numerator information for the incidence rates), while the accumulated person-years at risk of the cohort are estimated from a random sample from the cohort, i.e., the subcohort (providing denominator information for the incidence rates). Following this approach, a subcohort of 2,589 women was sampled after the baseline exposure measurement. The subcohort has been followed up biennially by mail for vital status information. The vital status of subcohort members, who did not respond was completed by contacting the municipal population registers. Incident cases occurring in the entire cohort were detected by annual record linkages to the Netherlands Cancer Registry and the nationwide network and registry of histopathology and cytopathology in the Netherlands (PALGA). Further details on the design of the study and methods of follow-up have been presented elsewhere [31, 32].

The present analysis is restricted to cancer incidence in the 11.3-year follow-up period from September 1986 to December 1997. The completeness of cancer follow up was estimated to be at least $96 \%$ [33], and no subcohort members were lost to follow up.

Three hundred and twenty-seven incident, microscopically confirmed, invasive, primary endometrial carcinomas were detected after a follow-up period of 11.3 years. Cases were excluded from analysis if they had been diagnosed with non-epithelial tumors $(n=12)$, and if information on either alcohol consumption or cigarette smoking was incomplete $(n=35)$.

Women were eligible for the subcohort if they did not report at baseline that they had undergone hysterectomy. Application of this inclusion criterion yielded a subcohort of 2,229 members. Individuals were excluded from the analysis if they had been diagnosed with cancer other than skin cancer at baseline $(n=151)$ and if information on either alcohol consumption or cigarette smoking was missing $(n=177)$. After these exclusions, 280 cases and 1,901 subcohort members remained available for analysis.

\section{Questionnaire data}

Consumption of alcoholic beverages during the year preceding the baseline interview was assessed by consumption frequency questions on beer, red wine, white wine, sherry, other fortified wine, liqueur, and liquor. Categories ranked from 'never' to ' $6-7$ times per week' and information on the number of glasses per consumption day was also requested. Questionnaire data of all cases and subcohort members were key entered twice and processed in a manner blinded with regard to case/subcohort status in order to minimize observer bias in the coding and 
interpretation of data. The questionnaire has been validated against a nine-day diet record [34, 35]. The Pearson correlation coefficient between the mean daily ethanol intake assessed by the questionnaire and that estimated by the nine-day record was 0.86 for all subjects and 0.78 for users of alcoholic beverages [34]. Respondents that reported to drink alcohol less than once per month were considered non-drinkers. Four items from the questionnaire (red wine, white wine, sherry, and liqueur) were combined into one single wine variable since these items were highly correlated and separate analysis would have resulted in small numbers of subjects within each stratum. Mean daily alcohol consumption was calculated using the Dutch food composition table [36]. Based on data from a pilot study, standard glasses were defined as follows: $200 \mathrm{ml}$ for beer, $105 \mathrm{ml}$ for wine, $80 \mathrm{ml}$ for sherry, and $45 \mathrm{ml}$ for both liqueur and liquor, corresponding to $8 \mathrm{~g}, 10 \mathrm{~g}, 11 \mathrm{~g}, 7 \mathrm{~g}$, and $13 \mathrm{~g}$ of alcohol, respectively.

Smoking was addressed at baseline by questions on age at first exposure to smoking, age at last exposure to smoking, smoking frequency, and smoking duration of cigarette, cigar, and pipe smokers. As the vast majority of smoking subcohort members was cigarette smokers, analyses were restricted to that particular group. Based on the questionnaire data, the following cigarette smoking variables were constructed: cigarette smoking status (never versus ever and never versus former or current), frequency (number of cigarettes per day), duration (years), age at first exposure (years), and time since cessation (years). Time since cessation was calculated as 'age at baseline' minus 'age at smoking cessation'.

Concerning the use of HRT, women were asked whether they had ever used HRT because of complaints related to the menopause. We can assume that all members of our cohort were postmenopausal in 1986, when the baseline questionnaires were completed, and that possible treatment with HRT took place prior to 1986 in most women. Based on information regarding HRT prescription in the Netherlands in the past [37-39], we assume that all HRT users enrolled in the NLCS were treated with unopposed oral estrogens.

\section{Data analysis}

A variable was considered a confounder if (I) it was associated with endometrial cancer risk, if (II) it was associated with alcohol consumption or cigarette smoking, and if (III) age-adjusted hazard ratios changed by more than $10 \%$ after adjustment for the potentially confounding factor. Based on the literature [40] and previous analyses, we considered the following variables as potential confounders: age (continuous), age at menarche (continuous), use of oral contraceptives (ever versus never), duration of oral contraceptive use (continuous), age at first child birth (continuous), parity (continuous), age at menopause (continuous), use of postmenopausal hormones (ever versus never), duration of postmenopausal hormone use (continuous), non-occupational physical activity (categorized), BMI (continuous), height (continuous), energy intake (continuous), total fat intake (continuous), intake of saturated fat (continuous), intake of carbohydrates (continuous), intake of dietary fiber (continuous), intake of vegetables (continuous), intake of fruits (continuous), coffee consumption (yes versus no), education (categorized), diagnosis of hypertension (yes versus no), diagnosis of diabetes mellitus (yes versus no), family history of endometrial cancer (yes versus no), and if applicable: total alcohol consumption per day (continuous), type of alcoholic beverage (categorized), current smoking (yes versus no), number of cigarettes smoked per day (continuous), and duration of smoking (continuous).

Incidence rate ratios (RR) and corresponding 95 percent confidence intervals (95\% CI) for endometrial cancer were estimated in the age-adjusted and multivariate case-cohort analyses with categorized and continuous alcohol and cigarette smoking variables, using the Cox proportional hazards model [41] processed with the Stata statistical software package [42]. Standard errors were estimated using the robust Hubert-White sandwich estimator to account for additional variance introduced by sampling from the cohort. This method is equivalent to the variancecovariance estimator by Barlow [43]. The proportional hazards assumption was tested using the scaled Schoenfeld residuals [44]. Tests for dose-response trends in risk of endometrial cancer were assessed by fitting ordinal exposure variables as continuous terms. Tests for interaction were performed by using the Wald test. Two-sided $p$ values are reported throughout the paper.

\section{Results}

The percentage of women reporting alcohol consumption was similar among cases and subcohort members $(67.5 \%$ and $66.9 \%$, respectively), as was the mean alcohol consumption per day among users in both groups $(7.7 \mathrm{~g}$ with standard deviation $(\mathrm{sd})=10.8$, and $8.5 \mathrm{~g}(\mathrm{sd}=10.4)$, respectively). Current smoking was less prevalent among cases than among subcohort members (15.4\% vs. $21.8 \%)$, but the number of cigarettes smoked per day did not differ considerably between smokers in both groups (13.6 $(\mathrm{sd}=8.4)$ and $13.2(\mathrm{sd}=8.1)$, respectively $)$.

Drinkers reported a slightly higher age at menopause and a higher prevalence of both oral contraceptive use and current cigarette smoking than non-drinkers (see Table 1). With regard to smoking status, former and current smokers were slightly leaner and had fewer children 
Table 1 Means (standard deviation) and distribution $(n)$ of potential confounders according to alcohol consumption and cigarette smoking status among subcohort members, the Netherlands Cohort Study (1986-1995)

\begin{tabular}{|c|c|c|c|c|c|c|}
\hline \multirow[t]{2}{*}{ Characteristic } & \multirow[t]{2}{*}{ Unit } & \multicolumn{2}{|c|}{ Alcohol consumption status } & \multicolumn{3}{|c|}{ Cigarette smoking status } \\
\hline & & $\begin{array}{l}\text { No } \\
(n=630) \\
\text { Mean }(\mathrm{sd})\end{array}$ & $\begin{array}{l}\text { Yes } \\
(n=1,271) \\
\text { Mean (sd) }\end{array}$ & $\begin{array}{l}\text { Never } \\
(n=1,100) \\
\text { Mean }(\mathrm{sd})\end{array}$ & $\begin{array}{l}\text { Former } \\
(n=387) \\
\text { Mean (sd) }\end{array}$ & $\begin{array}{l}\text { Current } \\
(n=414) \\
\text { Mean (sd) }\end{array}$ \\
\hline Age & Years & $61.8(4.3)$ & $61.4(4.3)$ & $62.0(4.3)$ & $61.1(4.4)$ & $60.7(4.1)$ \\
\hline Body Mass Index & $\mathrm{kg} / \mathrm{m}^{2}$ & $25.4(3.9)$ & $24.9(3.4)$ & $25.3(3.5)$ & $24.7(3.3)$ & $24.6(3.8)$ \\
\hline Parity & $\begin{array}{l}\text { Number of } \\
\text { children }\end{array}$ & $2.8(2.4)$ & $2.7(2.2)$ & $3.0(2.4)$ & $2.5(1.8)$ & $2.5(2.1)$ \\
\hline Age at 1 st child birth & Years & $22.0(11.2)$ & $21.9(11.3)$ & $22.2(11.2)$ & $22.3(11.3)$ & $20.8(11.3)$ \\
\hline Age at menopause & Years & $48.3(4.8)$ & $49.2(4.3)$ & $49.1(4.4)$ & $49.2(4.1)$ & $48.1(4.8)$ \\
\hline $\begin{array}{l}\text { Total energy intake (including } \\
\text { alcohol) }\end{array}$ & kcal & $1,628(415)$ & $1,724(386)$ & $1,694(393)$ & $1,676(406)$ & $1,705(406)$ \\
\hline Alcohol consumption & G/day & $0(0)$ & $8.5(10.4)$ & $5.7(7.8)$ & $10.4(11.2)$ & $12.5(12.8)$ \\
\hline \multirow[t]{2}{*}{ Cigarettes } & No./day & $13.0(8.8)$ & $11.1(8.1)$ & $0(0)$ & $9.8(8.0)$ & $13.2(8.1)$ \\
\hline & & $n(\%)^{\mathrm{a}}$ & $n(\%)^{\mathrm{a}}$ & $n(\%)^{\mathrm{a}}$ & $n(\%)^{\mathrm{a}}$ & $n(\%)^{\mathrm{a}}$ \\
\hline Oral contraceptive use & Ever & $124(20.0)$ & $336(26.7)$ & $223(20.6)$ & 127 (32.9) & $110(26.8)$ \\
\hline Physical activity & $>30 \mathrm{~min} /$ day & $425(69.1)$ & $975(77.8)$ & $796(74.1)$ & $306(79.5)$ & $298(72.9)$ \\
\hline Diagnosis of hypertension & Yes & $198(31.4)$ & 351 (27.6) & $339(30.8)$ & $107(27.7)$ & $103(24.9)$ \\
\hline Diagnosis of diabetes & Yes & $33(5.2)$ & $40(3.2)$ & $48(4.4)$ & $13(3.4)$ & $12(2.9)$ \\
\hline Hormone replacement therapy & Ever & $62(10.0)$ & $152(12.1)$ & $107(9.9)$ & $58(15.1)$ & $49(12.0)$ \\
\hline Family history of endometrial cancer & Yes & $20(3.2)$ & $32(2.5)$ & $23(2.1)$ & $16(4.1)$ & $13(3.1)$ \\
\hline Alcohol users & Yes & - & - & $663(60.3)$ & $312(80.6)$ & $296(71.5)$ \\
\hline Currently smoking cigarettes & Yes & $118(18.7)$ & $296(23.3)$ & - & - & - \\
\hline
\end{tabular}

a The percentage reported for some variables does sometimes not correspond with the numbers per smoker stratum since part of the information for these variables was missing

than never-smokers. On average, current smokers reported having reached menopause 1 year earlier than formersmokers and never-smokers. The prevalence of both oral contraceptive use and alcohol use was higher among smokers than among never-smokers. Also, average alcohol consumption was approximately twice as high among smokers as among never-smokers (see Table 1).

Based on the literature and based on the methodological criteria specified above, we found the following confounders: age, BMI, parity, oral contraceptive use, nonoccupational physical activity, hypertension, age at first child birth, and age at menopause. Alcohol consumption and cigarette smoking status were found to confound each other's association with endometrial cancer. We controlled for all these confounders in multivariate analyses. In additional analyses, we mutually controlled the ageadjusted risk estimates regarding qualitative smoking measures for the other smoking measures.

The multivariate risk estimates did not change substantially when oral contraceptive use (ever/never) was replaced by duration of oral contraceptive use (data not shown). Accordingly, we considered it sufficient to control only for oral contraceptive use (ever/never).
Table 2 shows the results for the association between alcohol consumption and endometrial cancer. The multivariate adjusted RR associated with alcohol consumption was $1.06(95 \% \mathrm{CI}=0.78-1.43)$. The multivariate $\mathrm{RRs}$ of endometrial cancer for women who consumed up to 4, 5$14,15-29$, and 30 or more gram of alcohol per day versus non-drinkers were 1.09 (95\% CI $=0.78-1.52), 0.95(95 \%$ $\mathrm{CI}=0.62-1.45), 0.94(95 \% \mathrm{CI}=0.52-1.69)$, and 1.78 (95\% CI $=0.88-3.60)$, respectively. No significant trend was observed $\left(p_{\text {trend }}=0.62\right)$.

The multivariate RR of endometrial cancer for wineconsumers versus non-consumers was slightly, but nonsignificantly, elevated $(\mathrm{RR}=1.13,95 \% \mathrm{CI}=0.84-1.52)$. The RRs were also slightly, but non-significantly elevated when calculated according to different levels of wine consumption and no significant trend was observed $\left(p_{\text {trend }}=0.64\right)$. The multivariate RR of endometrial cancer associated with drinking beer equaled $1.30 \quad(95 \%$ $\mathrm{CI}=0.82-2.07)$ and the RR for drinking liquor was 1.11 $(95 \% \mathrm{CI}=0.73-1.68)$.

Regarding smoking, age-adjusted analysis revealed an inverse association between ever-smoking and endometrial cancer risk $(\mathrm{RR}=0.70,95 \% \mathrm{CI}=0.54-0.92$, see Table 3$)$. 
Table 2 Rate ratios of endometrial cancer according to baseline alcohol consumption in the Netherlands Cohort Study, 1986-1997

\begin{tabular}{|c|c|c|c|c|c|c|c|}
\hline \multirow{2}{*}{$\begin{array}{l}\text { Alcohol consumption } \\
\text { (g/ day) }\end{array}$} & \multicolumn{4}{|l|}{ Age adjusted } & \multicolumn{3}{|c|}{ Multivariate adjusted } \\
\hline & Categorical median & Cases & $\begin{array}{l}\text { Person-years } \\
\text { in subcohort }\end{array}$ & $\operatorname{RR}(95 \% \mathrm{CI})^{\mathrm{a}}$ & Cases & $\begin{array}{l}\text { Person-years } \\
\text { in subcohort }\end{array}$ & $\mathrm{RR}(95 \% \mathrm{CI})^{\mathrm{b}}$ \\
\hline \multicolumn{8}{|l|}{ Total alcohol } \\
\hline No & 0 & 91 & 6,641 & 1 (ref.) & 82 & 5,837 & 1 (ref.) \\
\hline Yes & 4.0 & 189 & 13,746 & $1.01(0.77-1.32)$ & 172 & 12,137 & $1.06(0.78-1.43)$ \\
\hline $0.1-4$ & 1.6 & 114 & 7,599 & $1.10(0.82-1.48)$ & 105 & 6,643 & $1.09(0.78-1.52)$ \\
\hline $5-14$ & 9.1 & 47 & 3,640 & $0.94(0.65-1.37)$ & 39 & 3,279 & $0.95(0.62-1.45)$ \\
\hline $15-29$ & 20.9 & 17 & 1,822 & $0.69(0.40-1.18)$ & 17 & 1,575 & $0.94(0.52-1.69)$ \\
\hline$\geq 30$ & 37.3 & 11 & 684 & $1.20(0.62-2.34)$ & 11 & 639 & $1.78(0.88-3.60)$ \\
\hline$p$ trend & & & & 0.49 & & & 0.62 \\
\hline \multicolumn{8}{|l|}{ Alcohol from wine } \\
\hline Yes & 3.2 & 182 & 13,009 & $1.06(0.81-1.37)$ & 166 & 11,507 & $1.13(0.84-1.52)$ \\
\hline $0.1-4$ & 1.5 & 125 & 8,072 & $1.17(0.88-1.55)$ & 112 & 7,113 & $1.16(0.84-1.59)$ \\
\hline $5-14$ & 8.9 & 38 & 3,146 & $0.91(0.61-1.36)$ & 35 & 2,784 & $1.07(0.68-1.67)$ \\
\hline$\geq 15$ & 21.8 & 19 & 1,791 & $0.80(0.48-1.35)$ & 19 & 1,611 & $1.11(0.64-1.93)$ \\
\hline$p$ trend & & & & 0.43 & & & 0.64 \\
\hline \multicolumn{8}{|l|}{ Alcohol from beer } \\
\hline Yes & 1.14 & 29 & 1,873 & $1.15(0.76-1.74)$ & 26 & 1,629 & $1.30(0.82-2.07)$ \\
\hline \multicolumn{8}{|l|}{ Alcohol from liquor } \\
\hline Yes & 3.7 & 34 & 2,648 & $0.93(0.64-1.37)$ & 31 & 2,349 & $1.11(0.73-1.68)$ \\
\hline
\end{tabular}

${ }^{\mathrm{a}} \mathrm{RR}=$ rate ratios; $\mathrm{CI}=$ confidence interval; n.a. = not applicable

${ }^{\mathrm{b}}$ Rate ratios adjusted for age (years), body mass index $\left(\mathrm{kg} / \mathrm{m}^{2}\right)$, parity (number of children), use of oral contraceptives (ever versus never), nonoccupational physical activity (low, moderate, active, very active), hypertension (yes versus no), age at first child birth (years), age at menopause (years), and current cigarette smoking (yes versus no)

We observed significant inverse trends of endometrial cancer risk with all quantitative smoking measures. However, these trends became non-significant when neversmokers were excluded. Some of these age-adjusted risk estimates changed substantially after additional adjustment for current smoking status, smoking frequency and smoking duration (see Table 3).

When we adjusted for all confounders, multivariate analysis showed a statistically significant $29 \%$ reduced risk of endometrial cancer for ever-smokers when contrasted with never-smokers. When considered separately, the risk reduction appeared to be stronger among current smokers $(\mathrm{RR}=0.59,95 \% \mathrm{CI}=0.40-0.88)$ than among former smokers $(\mathrm{RR}=0.83,95 \% \mathrm{CI}=0.58-1.20)$. Tests for trends were not significant for any of the quantitative smoking variables when these were adjusted for age and additional confounders.

The strongest reduction in risk, which could be observed in both univariate and multivariate models, was associated with a smoking history of 40 or more years compared with having never smoked $(\mathrm{RR}=0.37,95 \% \mathrm{CI}=0.15-0.90)$. Moreover, we observed a non-significant 50\% reduction in risk in women that quit smoking either nine or less years ago or that quit 10-19 years ago. The data indicated no association between age at first smoking exposure and endometrial cancer.

Omitting age at menopause and BMI from the multivariate models either separately or simultaneously did not cause meaningful changes in the corresponding estimates. No interactions in determining endometrial cancer risk could be observed between alcohol consumption and HRT use $(p=0.43)$, BMI $(p=0.38)$, age at menopause ( $p=0.39$ ), or current cigarette smoking $(p=0.83)$. When we stratified multivariate alcohol analyses according to smoking status, we observed a non-significantly lower risk of endometrial cancer among alcohol consumers that have ever smoked $(\mathrm{RR}=0.91,95 \% \mathrm{CI}=0.52-1.58)$ than among alcohol consumers that have never smoked $(\mathrm{RR}=1.16,95 \% \mathrm{CI}=0.81-1.67)$. Concerning smoking and HRT use, the interaction term was not statistically significant $(p=0.11)$. In this subset analysis, current smoking was associated with a reduced risk of endometrial cancer in women not using HRT $(\mathrm{RR}=0.54,95 \%$ $\mathrm{CI}=0.35-0.84)$. In current smokers that did use HRT, the $\mathrm{RR}$ was $1.32(95 \% \mathrm{CI}=0.57-3.04)$. Numbers were very small however: only 28 women were current smokers and used HRT and only eight women were current smokers and did not use HRT. 


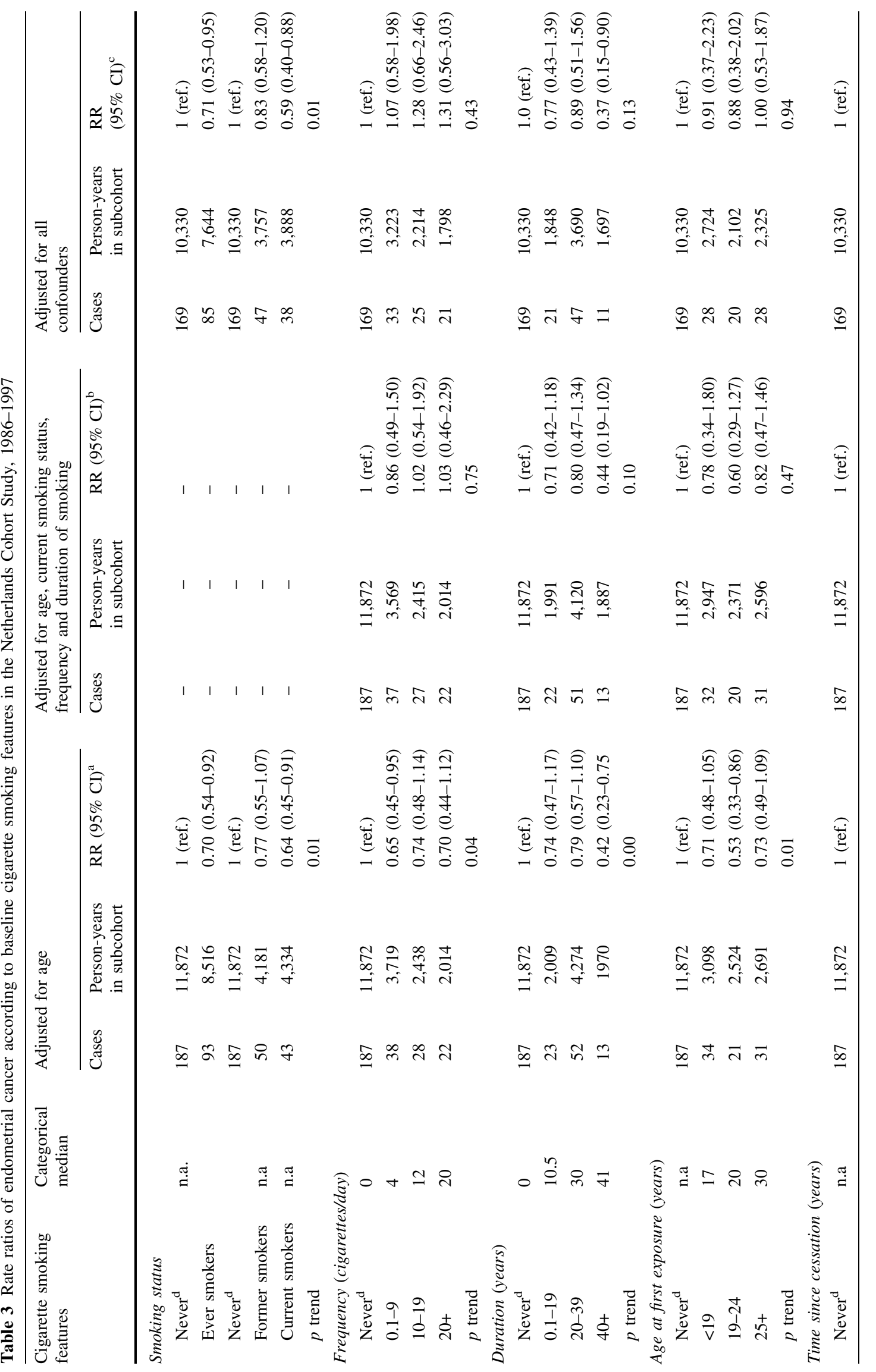




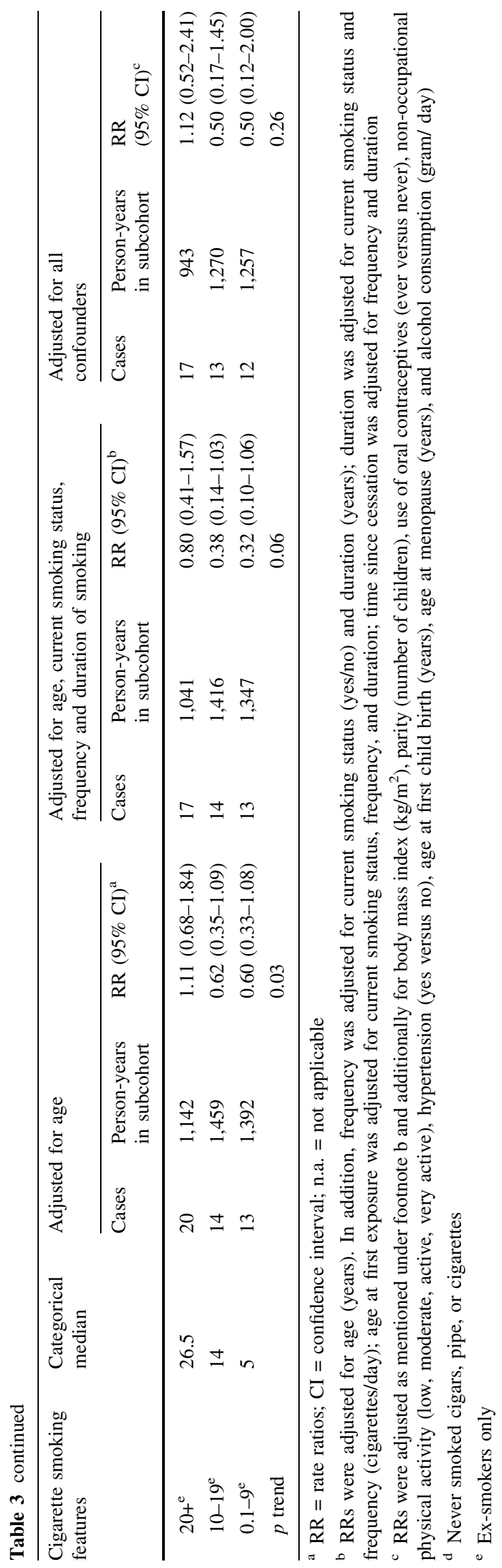

\section{Discussion}

Our results do not suggest a meaningful association between alcohol consumption and endometrial cancer risk. Current smoking is associated with a reduced risk of endometrial cancer. This inverse relationship is neither mediated by BMI nor by age at menopause.

Regarding the biological mechanism underlying endometrial carcinogenesis, the so-called "unopposed estrogen hypothesis" is widely accepted [2]. According to this hypothesis endometrial cancer develops when the endometrium is exposed to high levels of unopposed endogenous or exogenous estrogens for a long period of time. This exposure results in elevated mitotic proliferation of endometrial cells which, in turn, increases the risk of DNA replication errors and DNA mutations which can lead to endometrial cancer [2].

Although female alcohol consumers could be expected to be at increased risk of endometrial cancer due to their hormonal profile, we have not detected significant associations between alcohol consumption and endometrial cancer risk. This finding is consistent with the vast majority of previous studies [13, 15-18]. However, in the EPIC study, significantly elevated blood estrone levels were found only in postmenopausal women who consumed more than $25 \mathrm{~g}$ of alcohol per day compared to non-drinkers [3]. Thus, possibly, a marked increase in estrone concentrations, and ultimately in endometrial cancer risk, can only be observed in women who consume more than moderate amounts. This notion might be supported by our data as we have observed an (non-significantly) elevated risk of endometrial cancer in women who reported to drink more than $30 \mathrm{~g}$ of alcohol per day. Based on literature reviews $[7,8]$, we hypothesized that we might find a positive association between alcohol consumption and endometrial cancer risk in particular among HRT users. However, our findings do not support the hypothesis of an effect-modification by HRT use; neither did most of the previous epidemiological studies [13, 17, 18].

Concerning smoking, an anti-estrogenic effect has been suggested [23], which should lower the risk of endometrial cancer according to the unopposed estrogen hypothesis. Accordingly, our data indicated a significant risk reduction in current smokers, just like the Nurses' Health Study did, which has reported a RR of $0.72(95 \% \mathrm{CI}=0.57-0.90)$ for current smokers [29]. In contrast, other cohort studies have observed non-significant associations [25, 26, 28]. We found that the inverse association between smoking and endometrial cancer was more pronounced among current smokers than among former smokers. These findings are in line with the evidence from several case-control [17, 45-47] and two cohort studies [26, 28] and they suggest that the degree of protection might partly depend on the time since smoking cessation. 
Although not statistically significant, our prospective data support this notion, because we observed that endometrial cancer risk is possibly higher in women that quit smoking 20 or more years ago compared to the risk in women that quit 19 years ago or less. In the epidemiological literature, a few studies presented data on time since cessation [17, 28, 29, 48-50], but only one of them found a significantly lowered risk among women that quit smoking less than 10 years ago [48].

Considering the risk associated with duration of smoking, we have observed a reduction in risk with a long smoking history, just like previous studies [17, 29, 47, 48].

With regard to smoking intensity, we have found that smoking 20 or more cigarettes per day is associated with a non-significantly elevated risk of endometrial cancer. Though one needs to bear in mind that the corresponding confidence intervals were large, these point estimates are possibly not in line with the majority of previous studies, which generally indicated that a high smoking intensity (e.g., smoking 20 or more cigarettes per day) is associated with a decreased risk of endometrial cancer $[17,22,28,29,45,47$, $48,51]$. This inconsistency could be explained by the lack of adjustment for other smoking variables in earlier studies: only one [29] out of six [22, 25-29] prospective cohort studies has adjusted its smoking frequency estimates for the potentially confounding effects of smoking duration. When we omitted smoking duration from our multivariate models, the RRs for smoking frequency also suggested an inverse association with endometrial cancer (data not shown).

Our results do not indicate any important association between the age at starting smoking and endometrial cancer risk. Four previous studies [26, 28, 47, 49] found a (non-significant) risk reduction with young age at first exposure, that is, starting to smoke between age 15 [28] or age 20 or earlier [49], but none of these studies has reported a significant trend.

It has been hypothesized that smoking might lower the levels of estrogens partly by reducing the amount of fat tissue or by decreasing the age at menopause [24]. In our cohort, smokers were slightly leaner than non-smokers $\left(24.6 \mathrm{~kg} / \mathrm{m}^{2}\right.$ vs. $\left.25.3 \mathrm{~kg} / \mathrm{m}^{2}\right)$. Moreover, on average, current smokers appeared to have reached menopause 1 year earlier than never-smokers and former smokers (48.1 years vs. 49.1 years). However, in conclusion, our analyses indicated that BMI and age at menopause are no mediating factors.

In contrast to smoking, use of unopposed HRT increases endometrial cancer risk in postmenopausal women. Although an interaction between smoking and HRT use seems biologically plausible, the small numbers in our analysis did not allow to draw firm conclusions regarding a possible effect modification by HRT use. Moreover, we had no precise information on what type of HRT women in the NLCS have used. If we could have included such information in our analysis, results might differ according to type of HRT used.

Another potential drawback of our study might be misclassification of self-reported alcohol consumption and/or self-reported cigarette smoking. However, these misclassifications might be non-differential owing to the prospective study design. Consequently, the risk estimates would probably be biased towards no effect. Moreover, the correlation between the alcohol consumption measured by the NLCS questionnaire and the measurement in a nine-day record was high due to the large variation in alcohol consumption [34].

An important strength of our study is that the exposures were assessed prior to the diagnosis of endometrial cancer. Therefore, our findings cannot be influenced by recall bias. Moreover, selection bias is unlikely as the follow-up of subcohort members and cases was almost complete [33, 52]. Another strength is the way alcohol consumption and cigarette smoking was assessed in the NLCS. The detailed assessment enabled us to evaluate associations between endometrial cancer and various measures of both exposures. Furthermore, we were able to control for confounding by the most important risk factors of endometrial cancer [40].

To sum up our major findings, we found that alcohol consumption is not associated with endometrial cancer. Current smoking was associated with a reduced risk of endometrial cancer in postmenopausal women. This association was probably not mediated by a decreased BMI or by an earlier age at menopause. Larger prospective studies with information on the type of HRT are needed in order to investigate possible effect modification by different types of HRT.

Possibly, the incidence of endometrial cancer could be reduced if smoking was more common in female populations; however, such a reduction would be overshadowed by a dramatically increasing incidence of many other chronic diseases. Thus, individuals should still be encouraged to quit or not to start smoking.

Acknowledgments We are indebted to the participants of this study and further wish to thank the cancer registries (IKA, IKL, IKMN, IKN, IKO, IKR, IKST, IKW, IKZ and VIKC), and the Netherlands nationwide registry of pathology (PALGA). We thank S. van de Crommert, H. Brants, W. van Dijk, M. Moll, J. Nelissen, A. Pisters, M. Jansen, H. van Montfort, L. van den Bosch, and J. Berben for assistance.Furthermore, we thank M. Pin-Brouns, pharmacist, from the Laurentius Hospital Roermond for providing information on the history of HRT use in the Netherlands.

\section{References}

1. Ferlay J, Bray F, Pisani P, Parkin DM (2004) GLOBOCAN 2002: Cancer Incidence, Mortality and Prevalence Worldwide, Version 2.0. In: IARC CancerBase No. 5. Lyon, IARC Press

2. Akhmedkhanov A, Zeleniuch-Jacquotte A, Toniolo P (2001) Role of exogenous and endogenous hormones in endometrial 
cancer: review of the evidence and research perspectives. Ann NY Acad Sci 943:296-315

3. Rinaldi S, Peeters PH, Bezemer ID et al (2006) Relationship of alcohol intake and sex steroid concentrations in blood in pre- and post-menopausal women: the European Prospective Investigation into Cancer and Nutrition. Cancer Causes Control 17:1033-1043

4. Lacey JV, Jr., Brinton LA, Lubin JH, Sherman ME, Schatzkin A, Schairer C (2005) Endometrial carcinoma risks among menopausal estrogen plus progestin and unopposed estrogen users in a cohort of postmenopausal women. Cancer Epidemiol Biomarkers Prev 14:1724-1731

5. Strom B, Schinnar R, Weber A et al (2006) Case-control study of postmenopausal hormone replacement therapy and endometrial cancer. Am J Epidemiol 164:775-786

6. Weiderpass E, Adami HO, Baron JA et al (1999) Risk of endometrial cancer following estrogen replacement with and without progestins. J Natl Cancer Inst 91:1131-1137

7. Purohit V (1998) Moderate alcohol consumption and estrogen levels in postmenopausal women: a review. Alcohol Clin Exp Res 22:994-997

8. Ginsburg ES (1999) Estrogen, alcohol and breast cancer risk. J Steroid Biochem Mol Biol 69:299-306

9. Bandera EV, Kushi LH, Olson SH, Chen WY, Muti P (2003) Alcohol consumption and endometrial cancer: some unresolved issues. Nutr Cancer 45:24-29

10. Williams RR, Horm JW (1977) Association of cancer sites with tobacco and alcohol consumption and socioeconomic status of patients: interview study from the Third National Cancer Survey. J Natl Cancer Inst 58:525-547

11. Webster LA, Weiss NS (1989) Alcoholic beverage consumption and the risk of endometrial cancer. Cancer and Steroid Hormone Study Group. Int J Epidemiol 18:786-791

12. Levi F, Franceschi S, Negri E, La Vecchia C (1993) Dietary factors and the risk of endometrial cancer. Cancer 71:3575-3581

13. Swanson CA, Wilbanks GD, Twiggs LB et al (1993) Moderate alcohol consumption and the risk of endometrial cancer. Epidemiology 4:530-536

14. Parazzini F, La Vecchia C, D’Avanzo B, Moroni S, Chatenoud L, Ricci E (1995) Alcohol and endometrial cancer risk: findings from an Italian case-control study. Nutr Cancer 23:55-62

15. Goodman MT, Hankin JH, Wilkens LR et al (1997) Diet, body size, physical activity, and the risk of endometrial cancer. Cancer Res 57:5077-5085

16. Newcomb PA, Trentham-Dietz A, Storer BE (1997) Alcohol consumption in relation to endometrial cancer risk. Cancer Epidemiol Biomarkers Prev 6:775-778

17. Weiderpass E, Baron JA (2001) Cigarette smoking, alcohol consumption, and endometrial cancer risk: a population-based study in Sweden. Cancer Causes Control 12:239-247

18. Gapstur SM, Potter JD, Sellers TA, Kushi LH, Folsom AR (1993) Alcohol consumption and postmenopausal endometrial cancer: results from the Iowa Women's Health Study. Cancer Causes Control 4:323-329

19. Austin H, Drews C, Partridge EE (1993) A case-control study of endometrial cancer in relation to cigarette smoking, serum estrogen levels, and alcohol use. Am J Obstet Gynecol 169:10861091

20. Jain MG, Howe GR, Rohan TE (2000) Nutritional factors and endometrial cancer in Ontario, Canada. Cancer Control 7:288-296

21. Jain MG, Rohan TE, Howe GR, Miller AB (2000) A cohort study of nutritional factors and endometrial cancer. Eur J Epidemiol 16:899-905

22. Terry $\mathrm{P}$, Baron JA, Weiderpass E, Yuen J, Lichtenstein P, Nyren O (1999) Lifestyle and endometrial cancer risk: a cohort study from the Swedish Twin Registry. Int J Cancer 82:38-42
23. Baron JA (1984) Smoking and estrogen-related disease. Am J Epidemiol 119:9-22

24. Terry PD, Rohan TE, Franceschi S, Weiderpass E (2002) Cigarette smoking and the risk of endometrial cancer. Lancet Oncol 3:470-480

25. Engeland A, Andersen A, Haldorsen T, Tretli S (1996) Smoking habits and risk of cancers other than lung cancer: 28 years' follow-up of 26,000 Norwegian men and women. Cancer Causes Control 7:497-506

26. Nordlund LA, Carstensen JM, Pershagen G (1997) Cancer incidence in female smokers: a 26-year follow-up. Int J Cancer 73:625-628

27. Tulinius H, Sigfusson N, Sigvaldason H, Bjarnadottir K, Tryggvadottir L (1997) Risk factors for malignant diseases: a cohort study on a population of 22,946 Icelanders. Cancer Epidemiol Biomarkers Prev 6:863-873

28. Terry PD, Miller AB, Rohan TE (2002) A prospective cohort study of cigarette smoking and the risk of endometrial cancer. Br J Cancer 86:1430-1435

29. Viswanathan AN, Feskanich D, De Vivo I et al (2005) Smoking and the risk of endometrial cancer: Results from the Nurses' Health Study. Int J Cancer 114:996-1001

30. IARC Working Group on the Evaluation of Carcinogenic Risks to Humans (2004) Tobacco smoke and involuntary smoking. Lyon, France: IARCPress

31. Van den Brandt PA, Schouten LJ, Goldbohm RA, Dorant E, Hunen PM (1990) Development of a record linkage protocol for use in the Dutch Cancer Registry for Epidemiological Research. Int J Epidemiol 19:553-558

32. van den Brandt PA, Goldbohm RA, van't Veer P, Volovics A, Hermus RJ, Sturmans F (1990) A large-scale prospective cohort study on diet and cancer in the Netherlands. J Clin Epidemiol 43:285-295

33. Goldbohm RA, van den Brandt PA, Dorant E (1994) Estimation of the coverage of Dutch municipalities by cancer registries and PALGA based on hospital discharge data. Tijdschr Soc Gezondheidsz 72:80-84

34. Goldbohm RA, van den Brandt PA, Brants HA et al (1994) Validation of a dietary questionnaire used in a large-scale prospective cohort study on diet and cancer. Eur J Clin Nutr 48:253-265

35. Goldbohm RA, van't Veer P, van den Brandt PA et al (1995) Reproducibility of a food frequency questionnaire and stability of dietary habits determined from five annually repeated measurements. Eur J Clin Nutr 49:420-429

36. Stichting NEVO (1986) NEVO-table; Dutch food composition table 1986-1987. Voorlichtingsbureau voor de Voeding, The Hague, the Netherlands

37. Reijnders L, Buurma H, Vulto A (1981) Geneesmiddelen in Nederland: gids voor arts en gebruiker (in Dutch). Van Gennep, Amsterdam

38. Goodman Gilman A, Goodman LS, Gilman AZ (1985) Goodman and Gilman's the pharmacological basis of therapeutics. Macmillan Publ. Co, New York

39. Hamerlynck JV (1988) De medicalisering van de postmenopauze (in Dutch). Ned Tijdschr Geneeskd 132:1518-1523

40. Purdie DM, Green AC (2001) Epidemiology of endometrial cancer. Best Pract Res Clin Obstet Gynaecol 15:341-354

41. Cox DR (1972) Regression models and life-tables (with discussion). J R Statist Soc B 34:187-220

42. Cleves MA, Gould WW, Gutierrez RG (2002) An introduction to survival analysis using stata. Stata Press, Texas

43. Barlow WE (1994) Robust variance estimation for the casecohort design. Biometrics 50:1064-1072

44. Schoenfeld D (1982) Partial residuals for the proportional hazards regression model. Biometrika 69:239-241 
45. Lesko SM, Rosenberg L, Kaufman DW et al (1985) Cigarette smoking and the risk of endometrial cancer. $\mathrm{N}$ Engl $\mathrm{J}$ Med 313:593-596

46. Levi F, La Vecchia C, Decarli A (1987) Cigarette smoking and the risk of endometrial cancer. Eur J Cancer Clin Oncol 23:1025-1029

47. Brinton LA, Barrett RJ, Berman ML, Mortel R, Twiggs LB, Wilbanks GD (1993) Cigarette smoking and the risk of endometrial cancer. Am J Epidemiol 137:281-291

48. Parazzini F, La Vecchia C, Negri E, Moroni S, Chatenoud L (1995) Smoking and risk of endometrial cancer: results from an Italian case-control study. Gynecol Oncol 56:195-199
49. Newcomer LM, Newcomb PA, Trentham-Dietz A, Storer BE (2001) Hormonal risk factors for endometrial cancer: modification by cigarette smoking (United States). Cancer Causes Control 12:829-835

50. Weir HK, Sloan M, Kreiger N (1994) The relationship between cigarette smoking and the risk of endometrial neoplasms. Int $\mathbf{J}$ Epidemiol 23:261-266

51. Stockwell HG, Lyman GH (1987) Cigarette smoking and the risk of female reproductive cancer. Am J Obstet Gynecol 157:35-40

52. van den Brandt PA, van't Veer P, Goldbohm RA et al (1993) A prospective cohort study on dietary fat and the risk of postmenopausal breast cancer. Cancer Res 53:75-82 